\title{
EDUCAÇÃO INCLUSIVA: O OLHAR DO PROFESSOR SOBRE A PRÁTICA PEDAGÓGICA PARA O ALUNO COM DEFICIÊNCIA NO ENSINO FUNDAMENTAL II
}

\author{
INCLUSIVE EDUCATION: A TEACHER'S VIEW ABOUT THE PEDAGOGIC \\ PRACTICE TO STUDENT WITH DISABILITY IN ELEMENTARY SCHOOL II
}

\author{
Juliana Cavalcante de Andrade LOUZADA ${ }^{\mathrm{i}}$ \\ Sandra Eli Sartoreto de Oliveira MARTINS ${ }^{\text {ii }}$
}

RESUMO: O objetivo do estudo foi investigar a visão do professor sobre o trabalho pedagógico com alunos público-alvo da educação especial (PAEE) no ensino fundamental II. Participaram do estudo duas professoras de uma escola da rede estadual de ensino, que atuam em sala de aula comum em diferentes áreas do conhecimento. Trata-se de um Estudo de Caso de abordagem qualitativa, que adotou como instrumento de coleta de dados um roteiro de entrevista semiestruturado. Posterior à realização das entrevistas, foi feita a transcrição das gravações na íntegra a fỉm de obter os dados para análise. A análise desse material foi realizada a partir da Análise de Conteúdo de Bardin (2011). Os resultados revelam o conhecimento dos participantes sobre os apoios pedagógicos especializados ofertados aos alunos PAEE para cursar o ensino fundamental. Embora reconheçam a importância desse suporte, indicam a falta de qualificação profissional para orientá-los na apropriação do currículo em sala de aula comum. Somadas a esse aspecto, considerar como os professores buscam diminuir a exclusão e qualificar o rendimento escolar para esse alunado nesta etapa de ensino, constitui-se a tônica deste estudo.

PALAVRAS-CHAVE: Inclusão escolar. Ensino fundamental. Educação especial.

\section{ABSTRACT}

The aim of the study was to investigate the teacher's view about the pedagogic work with students target public in special education (PTSE) in elementary school II. Two teachers from a public school who work with regular classroom in different areas participated on this study. This is a case study with qualitative approach, that has adopted the semistructured interview as instrument. After the interviews, the recordings were transcribed literally in order to obtain the data for analysis. The data was analyzed through Content Analysis according to Bardin (1977). The results suggest the participant's knowledge about the specialized pedagogic support offered to PTSE students to attend the elementary school. Although the tea cher recognizes the support importance, they have indicated a lack of professional qualification to guide about the curriculum ownership in regular classroom. In addition, to consider how the teachers try to decrease the exclusion and how to qualify the scholar results for these students constitutes the goal of this study.

KEYWORDS: Schoolar inclusion. Elementary school. Special education. 


\section{Introdução}

De acordo com as Diretrizes Curriculares Nacionais da Educação Básica (2013)

o Ensino Fundamental tem constituído foco central da luta pelo direito à educação. Em consequência, no Brasil, nos últimos anos, sua organização e seu funcionamento têm sido objetivo de mudanças que se refletem nas expectativas de melhoria de sua qualidade e de ampliação de sua abrangência, consubstanciadas em novas leis, normas, sistemas de financiamento, sistemas de avaliação e monitoramento, programas de formação e aperfeiçoamento de professores e, o mais importante, em preocupações cada vez mais acentuadas quanto à necessidade de um currículo e de novos projetos político-pedagógicos que sejam capazes de dar conta dos grandes desafios da contemporaneidade (BRASIL, 2013, p.103).

O Ensino Fundamental com duração de 9 anos atende alunos com idade entre 6 (seis) e 14 (catorze) anos, estendendo-se àqueles que não conseguiram completá-lo em idade apropriada, ou então não tiveram condições de frequentá-lo. É nesse nível de escolarização que se encontram crianças e adolescentes com os mais diversos interesses, resultantes da interação de suas múltiplas experiências culturais e sociais (BRASIL, 2013). Nesse período da escolarização ocorre também uma série de transformações físicas, sociais e cognitivas ao longo do processo de desenvolvimento desses jovens, o que se reflete em sala de aula nos diferentes padrões de comportamento.

Além dos diferentes padrões de comportamento, fruto das experiências que essas crianças e adolescentes vivenciam ao longo de suas vidas, o professor encontra em sua sala de aula padrões de comportamento resultantes de uma deficiência congênita ou adquirida e que de forma inferior, similar ou superior, interferem no processo de ensinoaprendizagem desses jovens. Conforme retrata a Declaração de Salamanca (BRASIL, 1990), que prevê medidas para possibilitar a igualdade de acesso à educação para todos os alunos, incluindo os que apresentam necessidades educacionais especiais, dentre os quais destacam àqueles com deficiência, designado pelas políticas atuais como públicoalvo da Educação Especial (PAEE) (BRASIL, 2008; 2011). Caracteriza-se como público-alvo da educação especial os alunos com deficiência, transtornos globais do desenvolvimento, altas habilidades e superdotação (BRASIL, 2011).

Desse modo, o presente trabalho teve como objetivo investigar como se dá o trabalho pedagógico com alunos público-alvo da educação especial (PAEE) no ensino fundamental, uma vez que políticas públicas foram criadas para que estes alunos sejam 
atendidos de forma eficiente, e tenham o seu processo de ensino-aprendizagem contemplado na sala de aula regular.

\section{Método}

Trata-se de um estudo de caso de natureza qualitativa, realizado como parte dos requisitos de avaliação da disciplina "Trabalho docente no contexto da inclusão escolar", desenvolvida no programa de pós-graduação em Educação Escolar da FCL/UNESP de Araraquara. Para Coutinho e Chaves (2002), quase tudo pode ser um "caso": um indivíduo, um personagem, um grupo, uma organização, uma comunidade ou mesmo uma nação. Nesse sentido, o trabalho foi desenvolvido em uma escola da rede pública estadual, localizada no interior do estado de São Paulo, que oferece atendimento aos anos finais do ensino fundamental e ensino médio. A referida escola atende aproximadamente 700 alunos, dos quais 10 são PAEE. No ensino fundamental, nível de ensino foco da presente investigação, a escola apresenta 06 alunos PAEE.

\section{Sujeitos}

Participaram da pesquisa duas professoras da rede pública estadual de ensino do município de Bauru. A fim de manter o sigilo de identificação dos participantes adotaram-se as seguintes representações para identifica-los: "A" e "C". Optou-se por entrevistar duas professoras, sendo uma da área de códigos, linguagens e suas tecnologias e outra da área de ciências da natureza e suas tecnologias, que recebem alunos PAEE em sala de aula regular;; vale ressaltar que esses alunos recebem no contra turno o atendimento pedagógico especializado (APE) conforme a resolução SE 61, de 11 de novembro de 2014, que dispõe sobre a Educação Especial nas unidades escolares da rede estadual de ensino (BRASIL, 2014). O quadro 1 apresenta as informações acerca da carreira profissional de cada um dos sujeitos. 
Quadro 1. Identificação e histórico profissional dos sujeitos da pesquisa.

\begin{tabular}{|l|l|l|}
\hline Identificação & \multicolumn{1}{|c|}{ Professor “A” } & \multicolumn{1}{c|}{ Professor "C" } \\
\hline Tempo de atuação docente & 21 anos & 22 anos \\
\hline Formação Acadêmica & $\begin{array}{l}\text { Ensino Médio Comum } \\
(1988)\end{array}$ & Magistério (1985) \\
\hline $\begin{array}{l}\text { Formação Acadêmica } \\
\text { Superior }\end{array}$ & Artes Plásticas (1993) & $\begin{array}{l}\text { Ciências/Biologia (1993); } \\
\text { Matemática (2001). }\end{array}$ \\
\hline Pós-Graduação & $\begin{array}{l}\text { Especialização em Tecnologias } \\
\text { (EAD) (2014) }\end{array}$ \\
\hline Nível de ensino que atua & $\begin{array}{l}\text { Ensino Fundamental II e } \\
\text { Médio }\end{array}$ & Ensino Fundamental II \\
\hline Disciplina que ministra & Arte & Ciências \\
\hline $\begin{array}{l}\text { Tipo de deficiência do aluno } \\
\text { que atende }\end{array}$ & $\begin{array}{l}\text { Aluno 1: Deficiência } \\
\text { Intelectual } \\
\text { Aluno 2: Paralisia Cerebral }\end{array}$ & Aluno 2: Paralisia Cerebral \\
\hline
\end{tabular}

Fonte: Elaboração própria.

As duas professoras entrevistadas atendem uma aluna com 14 anos que está no $9^{\circ}$ ano do ensino fundamental. A referida aluna tem paralisia cerebral e, por este motivo, utiliza cadeira de rodas, tem movimentos restritos de membros superiores, faz uso de comunicação alternativa e conta com o apoio de um cuidador para frequentar a escola. De acordo com alguns autores, são possíveis características da paralisia cerebral, além do comprometimento motor que é marcante da deficiência, os déficits associados a problemas sensoriais e mentais (PATO et al, 2002). A professora "A" atende também em outra turma, uma aluna com 17 anos que está no $9^{\circ}$ ano do ensino fundamental e apresenta laudo de deficiência intelectual. Para a American Association of Mental Retardation (2002), a deficiência intelectual é compreendida numa perspectiva multidimensional, funcional e biológica, que tem como características limitações significativas no funcionamento intelectual e no comportamento adaptativo, como expresso nas habilidades práticas, sociais e conceituais. Por outro lado, existem ainda a concepção social e a médica acerca da deficiência intelectual que abordam sua definição por outros pontos de vista (MILIAN et al, 2013).

\section{Procedimento de coleta de dados}

O procedimento adotado para a coleta de dados foi a entrevista semiestruturada;; para Manzini (2003), o uso desse instrumento oferece segurança ao pesquisador ao 
entrevistar, devido ao fato de haver um roteiro com perguntas abertas auxiliando na organização da coleta de informações. Por tratar-se de uma pesquisa que faz parte de uma disciplina do programa de pós-graduação da FCL/UNESP-Araraquara, o referido roteiro foi previamente elaborado pela professora responsável pela disciplina, com o intuito de atender aos objetivos propostos.

As entrevistas foram realizadas em ambiente escolar com as duas professoras participantes, em horário de trabalho pedagógico, conforme autorizado pela coordenação pedagógica da escola. Cada entrevista teve duração média de aproximadamente 10 minutos.

\section{Aspectos éticos da pesquisa}

A direção da escola foi consultada quanto à possibilidade de realização das entrevistas com os docentes, e foi realizada a apresentação de um breve texto de apresentação da disciplina e intenções da pesquisa, a fim de esclarecer os objetivos propostos e firmar o compromisso de sigilo de identidade com os participantes e a instituição de ensino.

\section{Análise dos dados}

Todos os dados coletados nas entrevistas foram transcritos e os dados documentais sistematizados para posterior tratamento e análise dos mesmos a partir da Análise de Conteúdo (BARDIN, 2011; FRANCO, 2008), que se caracteriza por um conjunto de técnicas que tem como ponto de partida a mensagem, seja ela verbal (oral ou escrita), gestual, documental, silenciosa, figurativa ou diretamente provocada.

A técnica de análise de conteúdo permitirá analisar os conteúdos recolhidos no estudo a partir da análise temática, visando atender aos objetivos do estudo. Para dar início à análise temática, é preciso realizar a categorização, uma operação de classificação dos elementos que constituem o conjunto de dados, por diferenciação e seguidamente, por um reagrupamento. A categorização é a passagem dos dados brutos a dados organizados (BARDIN, 2011). 
Este tipo de análise foi utilizada por outros autores que trabalharam com análise documental em suas pesquisas (CHACON, 2004; VELDEN, 2012). Chacon (2004) utilizou a análise de conteúdo para identificar disciplinas de Educação Especial surgidas após a recomendação da Portaria 1.793/94.

Diante do conteúdo das entrevistas foram definidos dois grandes eixos temáticos, a saber:

A) O papel da escola: caracterizado por questões que abordavam iniciativas que a escola deve ou deveria ter tomado frente à situação de receber a matrícula de um aluno PAEE.

B) O olhar do professor: caracterizado por questões que abordavam o olhar do professor frente a diferentes situações que envolvem a relação do aluno PAEE com a escola, com o processo de ensino-aprendizagem e com os colegas de classe.

Após a definição dos eixos, cada um deles foi subdividido em categorias, como demonstram os quadros 2 e 3 .

Quadro 2. Apresentação e descrição das categorias de análise do eixo temático "O Papel da Escola"

\begin{tabular}{|l|l|}
\hline Categoria & Descrição \\
\hline 1. A gestão escolar como fonte de informação. & $\begin{array}{l}\text { Aborda os diferentes tipos de informações } \\
\text { fornecidas pela equipe gestora. }\end{array}$ \\
\hline 2. Acessibilidade e adaptações curriculares. & $\begin{array}{l}\text { Destaca aspectos de acessibilidade e } \\
\text { adaptações curriculares existentes na escola. }\end{array}$ \\
\hline 3. O Atendimento Pedagógico Especializado. & $\begin{array}{l}\text { Discorre sobre como se dá o serviço de apoio } \\
\text { pedagógico especializado na escola. }\end{array}$ \\
\hline
\end{tabular}

Fonte: Elaboração própria.

Quadro 3. Apresentação e descrição das categorias de análise do eixo temático "O Olhar do Professor"

\begin{tabular}{|l|l|}
\hline Categoria & Descrição \\
\hline 1. O lugar ideal para o aluno PAEE. & $\begin{array}{l}\text { Retrata a visão do professor sobre o lugar } \\
\text { ideal para o aluno PAEE. }\end{array}$ \\
\hline 2. A aprendizagem do aluno PAEE. & $\begin{array}{l}\text { Traz o relato do professor sobre a } \\
\text { aprendizagem do aluno PAEE. }\end{array}$ \\
\hline $\begin{array}{l}\text { 3. O As relações interpessoais do aluno } \\
\text { PAEE. }\end{array}$ & $\begin{array}{l}\text { Aponta o olhar do professor acerca das } \\
\text { relações interpessoais do aluno PAEE. }\end{array}$ \\
\hline
\end{tabular}

Fonte: Elaboração própria. 


\section{Resultados e discussão}

Com base nas informações retiradas das transcrições das entrevistas, pode-se concluir que as duas professores participantes da pesquisa exercem a carreira docente por opção e sentem-se realizadas com sua profissão, embora seja consenso entre elas que a tarefa docente não é algo simples, como se pode observar na fala da professora "A" "uma tarefa árdua né, mas prazerosa que a gente não só ensina, mas a gente aprende muito com eles né, eu acho que tem horas que a gente até aprende muito mais do que ensina".

O papel da escola frente à presença de um aluno público-alvo da educação especial é de informar aos docentes sobre a chegada desse público na escola, bem como subsidiar o trabalho do professor a fim de proporcionar o atendimento de qualidade a esses alunos conforme preconiza o Estatuto da Pessoa com Deficiência, lei 13.146 de 6 de Julho de 2015. Nesse aspecto as professoras entrevistadas neste trabalho relatam que foram informadas pela coordenadora pedagógica da escola sobre a chegada das alunas em suas salas de aula, além disso, uma das professoras ressaltou que recebeu da coordenação documentos referentes ao ano letivo anterior da aluna na escola para facilitar a organização das atividades escolares, bem como informações sobre o tipo de deficiência, como descrevem os trechos abaixo:

“... eu recebi a informação que uma delas era cadeirante, que ela não falava, mas que ela tinha o desenvolvimento intelectual bom, que ela correspondia o que a gente propunha e recebi da outra já que tinha muita dificuldade da leitura, escrita né, que ela esquecia muito as coisas, por exemplo, o que ela aprende hoje esquece amanhã, dessa forma. " (Professora "A").

"Eu tive no caso de uma das alunas, a apresentação da pasta dela que foi a professora do ano anterior que passou para a coordenação $e$ a coordenação repassou isso para mim, a pasta da aluna, do desenvolvimento do que ela conseguia, até onde ela tinha ido, o que ela conseguiu atingir. E da outra também, no caso o caderno né, não o portfólio, mas o caderninho dela. " (Professora “A”).

“... nas nossas reuniões de htpcs foi passado as orientações. " (Professora "C").

“... a gestão da escola tá o tempo todo orientando nas nossas reuniões.

" (Professora "C") 
Embora fique evidente que as professoras recebem orientações da equipe gestora da escola, elas ainda apontam a falta de recursos e de elementos facilitadores de práticas de ensino para atender aos alunos com demandas educacionais diversificadas em sala de aula comum. Outra preocupação frequente quando se tem um aluno PAEE na escola são as questões de acessibilidade, e entenda-se por acessibilidade

possibilidade e condição de alcance para utilização, com segurança e autonomia, de espaços, mobiliários, equipamentos urbanos, edificações, transportes, informação e comunicação, inclusive seus sistemas e tecnologias, bem como de outros serviços e instalações abertos ao público, de uso público ou privados de uso coletivo, tanto na zona urbana como na rural, por pessoa com deficiência ou com mobilidade reduzida (BRASIL, 2015, p.1, grifos do autor).

Nesse caso, a aluna com paralisia cerebral teve o suporte da escola para providenciar o mobiliário adequado para que ela pudesse desenvolver suas atividades, conforme relata a professora "A" quando afirma que "teve que adaptar a carteira, e a prancha pra escrita".

Ainda sobre o papel da escola, o Decreto $n^{\circ} 6.571 / 2008$ e a resolução $n^{\circ}$ 7.611/2011, dispõe sobre a educação especial, o atendimento educacional especializado e dá outras providências, e estabelece no Art. 2 que, "a educação especial deve garantir os serviços de apoio especializado voltado a eliminar as barreiras que possam obstruir o processo de escolarização de estudantes com deficiências, transtornos globais do desenvolvimento e altas habilidades ou superdotação”.

Quando questionadas sobre a oferta de atendimento pedagógico especializado (APE) para essas alunas, as professoras afirmaram que a aluna com paralisia cerebral frequenta o APE, inclusive uma delas mencionou o termo "sala de recursos itinerante" e as duas disseram que o atendimento ocorre no contra turno escolar.

Outro aspecto importante a se considerar além do papel da escola quando se recebe um aluno PAEE, é o olhar do professor que irá atuar de maneira direta com esse aluno na sala de aula. Cabe ressaltar que a pedagogia a ser adotada deve ser aquela em que o foco é a criança, suas necessidades e potencialidades. São necessárias mudanças na forma com a qual a sociedade concebe estas pessoas, que por muito tempo inabilitam esses sujeitos, pois direcionam maior atenção aos seus impedimentos (BRASIL, 2015). Todavia, não basta que sejam valorizadas as potencialidades desses indivíduos se os profissionais que são destinados a atendê-los não estão capacitados para fazê-lo. 
Desse modo, ao longo da entrevista, quando foram questionadas sobre o lugar ideal para o aluno PAEE, foram obtidas duas respostas diferentes, embora apresentassem em comum alguns aspectos, como é possível observar nos trechos transcritos a seguir:

Pergunta: - Você considera a classe comum o lugar ideal para o atendimento desse aluno? Por quê?

"Eu até considero sim, mas não com a quantidade de alunos. Porque eu acho assim que eles têm que ter essa socialização e o aprendizado deles lógico que é diferente de outros alunos, porém, eu acho que não é legal que eles fiquem excluídos disso, mas muitos alunos em sala de aula atrapalha a gente. Por que a gente gostaria de dar uma atenção maior para esses alunos, poder desenvolver um trabalho melhor com eles, mas a gente acaba não conseguindo." (Professora " $A$ ").

"Seria melhor que ela tivesse assim um lugar que tivesse mais condições para que ela tivesse uma melhor informação, um trabalho mais diferenciado, acho que seria melhor pra ela ter um acompanhamento melhor, porque quando você trabalha com uma sala grande de 35 alunos, em muitos momentos fica difícil dar uma atenção especial pra ela. " (Professora " $C$ ").

Embora as duas professoras não compartilhem da mesma opinião quando se trata de manter ou não o aluno na classe comum, fica evidente que não há o cumprimento da Lei $\mathrm{n}^{\circ} 15.830$ de 15 de junho de 2015 que destaca em seu Art. $1^{\circ}$ a autorização ao poder executivo de limitar, em até 20 (vinte) alunos, o número de matrículas das salas de aula do ensino público fundamental e médio que têm matriculado 1 (um) aluno com necessidades especiais (BRASIL, 2015).

E, apesar dos entraves encontrados na sala de aula com o elevado número de alunos matriculados, quando abordamos a categoria "a aprendizagem do aluno PAEE" as duas professoras consideraram que o aprendizado das alunas é satisfatório. Para a professora "A", que ministra a disciplina de Arte, o aprendizado da aluna com paralisia cerebral não é considerado nem um pouco comprometido, uma vez que a professora considera seus conteúdos um tanto quanto abstratos e afirma que podem ser representados de diferentes formas, o que favorece a avaliação e bom desempenho da aluna nessa área. Para a professora "C", a aluna apresenta um desempenho satisfatório, no entanto, ela acredita que se a aluna fosse atendida em outro espaço poderia ter um melhor desempenho, como se pode observar na fala que segue 
“... a gente faz um trabalho diferenciado e ela tem esse acompanhamento, ela é muito inteligente e ela consegue acompanhar, mas não assim um trabalho como eu acho que deveria ser se ela tivesse o acesso a um lugar onde tivesse mais condições para ela aprender. " (Professora “C”).

Nesse aspecto, Bueno (2002) considera que práticas inclusivas devem considerar professores preparados para diminuir a exclusão escolar e qualificar o rendimento sem perder de vista que o papel da escola é atender as necessidades educacionais especiais e promover o desenvolvimento acadêmico de todos os alunos, inclusive dos que apresentam deficiências. Por outro lado, Gomes e Barbosa (2006) realizaram um estudo para avaliar as atitudes do professor quanto à inclusão de alunos com paralisia cerebral em classe comum, e concluíram que embora tenham sido contemplados em sua formação acadêmica com os saberes necessários para a prática docente, os professores participantes da pesquisa relataram não possuir preparo profissional para lidar com esta situação.

Na categoria "as relações interpessoais do aluno PAEE", houve um consenso por parte das respostas das professoras no que diz respeito ao relacionamento da aluna com paralisia cerebral e os demais alunos, bem como com relação à participação dos pais no contexto escolar. As professoras afirmam que ela tem um bom relacionamento com os colegas e uma delas diz que os alunos inclusive colaboram com ela durante as atividades. A participação dos pais no processo de escolarização da aluna ficou caracterizada pelo contato com a coordenação pedagógica da escola e o cumprimento das atividades extraclasse. As professoras atribuem o comprometimento da aluna com essas atividades a um bom acompanhamento dos pais em casa, como descreve a fala a seguir

“... a mãe está direto em contato com a escola. E vejo que ela esta sempre acompanhando a aluna e fazendo as atividades quando eu passo, ela participa o tempo todo. "(Professora “C”).

Para Eidelwein (2015), a inclusão de alunos com paralisia cerebral apresenta aspectos positivos para os estudantes e para a escola, pois promove mudanças no contexto escolar, com vistas a melhorar a qualidade do ensino para todos (EIDELWEIN, 2015), porém ao contrário nem sempre esta informação se faz recorrente. 
Cabe ressaltar que embora uma das professoras atendesse em sala de aula comum outra aluna PAEE com deficiência intelectual, pouco foi mencionado sobre essa aluna ao longo das entrevistas, e a única observação relevante feita com relação a essa aluna foi direcionada ao aspecto de relação interpessoal na qual a fala da professora revela um comportamento diferente dos alunos quando compara a aluna com paralisia cerebral e a aluna com deficiência intelectual, como o trecho abaixo demonstra

“... se tratando de uma das alunas há uma interação muito boa, a classe corresponde muito bem, respeita muito a aluna, não só pela condição intelectual, mas a condição física. Mas no caso da outra aluna já a classe não colabora muito, é deixada um pouco de lado pelos colegas, não tem uma interação, eles não conversam com ela. " (Professora " $A$ ").

Por fim, quando foram questionadas quanto à inclusão de alunos deficientes de uma forma geral no ensino comum as entrevistadas não se opõem, porém, reforçam a necessidade de orientação técnica para que o profissional que estiver em sala de aula com esses alunos possa exercer de maneira mais assertiva sua função. Como se pode observar na fala da professora "A", falta orientação aos professores, inclusive para preparar os demais alunos para receber o aluno PAEE.

\footnotetext{
"Olha, eu vejo até de uma forma boa, porém eu acho que o professor ele tinha que ser melhor orientado a respeito disso, porque na verdade a gente a acaba adaptando algumas coisas que na realidade, a gente nem sabe se realmente aquilo vai funcionar ou se é bom. Eu acho que nós deveríamos ter mais orientações técnicas a respeito disso, sei lá, cada um na sua área certinho, logicamente que não vai abranger todos, porque cada deficiência vai abranger a sua condição, uma diferente da outra, mas que a gente fosse melhor preparado pra gente também preparar os outros alunos dentro da sala de aula." (Professora " $A$ ").
}

Como define o próprio Ministério da Educação, as políticas de inclusão referem que não basta concretizar a matrícula dos alunos PAEE, mas sim "dar ao professor e à escola o suporte necessário à sua ação pedagógica” (BRASIL/MEC/SEESP, 1999b).

\section{Considerações finais}


A presente investigação revela que apesar de os professores reconhecerem a existência de apoios educacionais dirigidos aos alunos PAEE, como por exemplo - a oferta do serviço de apoio pedagógico especializado, se queixam da falta de subsídios para fundamentar a práticas de ensino no acolhimento as demandas educacionais desse alunado em sala de aula comum - lócus da atuação dos entrevistados. Dentre as dificuldades mais recorrentes para conduzir o trabalho docente destacam a ausência de procedimentos institucionais que reconheça e valorize a diferença, como parte constitutiva do humano nos processos de ensino e aprendizagem do alunado, inclusive daqueles que apresentam deficiência, como retratado. A superação da exclusão deste segmento populacional à apropriação dos conhecimentos acadêmicos valorizados culturalmente, aciona os envolvidos ao compromisso pelo reconhecimento dos ritmos e processos diferenciados de aprendizagem rumo à flexibilização do ensino e do currículo na escola. Os relatos partilhados são exemplos sobre os modos de organização do ensino para esse público no ensino fundamental que, dentre aspectos não ditos, revelam e retratam a realidade investigada.

\section{Referências}

American Association on Mental Retardation (AAMR). Mental retardation: definition, classification, and systems of supports. Washington: AAMR; 2002.

BARDIN, L. Análise de Conteúdo. Edição Revista e Ampliada. São Paulo: Edições 70, 2011.

BRASIL. Decreto no 6.571, de 17 de setembro de 2008 .

Lei n⿳ 13.146, de 06 de julho de 2015.

Lei $\mathbf{n}^{\mathbf{0}} \mathbf{1 5 . 8 3 0}$ de 15 de junho de 2015 .

. Ministério da Educação. Conferência Nacional da Educação Básica, 2008.

Ministério da Educação. Conferência Nacional da Educação, 2011.

Ministério da Educação. Conselho Nacional de Educação. Diretrizes

Curriculares Nacionais da Educação Básica. Brasília: MEC, SEB, DICEI, 2013.

. Ministério da Educação e do Desporto. Parâmetros Curriculares Nacionais adaptações curriculares: estratégias de ensino para a educação de alunos com necessidades educacionais especiais. Brasília: SEF: SEESP, 1999b. 
Resolução no 7.611 de 17 de novembro de 2011.

Resolução SE no 61 de 11 de novembro de 2014.

BUENO, J. G. S. Crianças com necessidades Educativas Especiais, Política Educacional e a Formação de Professores: Generalistas ou Especialistas? Revista Brasileira de Educação Especial. v.3, n. 5, p.7-25, 2002.

CHACON, M. C. M. Formação de recursos humanos em Educação Especial: resposta das universidades à recomendação da Portaria Ministerial $\mathrm{N}^{\circ}$ 1.793. Revista Brasileira de Educação Especial, v.10, n.3, p.321-336, 2004.

COUTINHO, C. P. e CHAVES, J. H. O estudo de caso na investigação em tecnologia educativa em Portugal. Revista Portuguesa de Educação, v. 15, n.1, p. 221-243, 2002.

EIDELWEIN, G. O desenvolvimento de um aluno com paralisia cerebral com a utilização do recurso da tecnologia assistiva no ensino regular. Signos. Ano 36, n.1, p. 86-101, 2015.

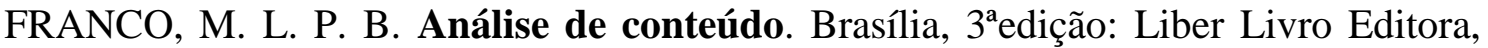
2008.

GOMES, C. e BARBOSA, A. J. G. Inclusão escolar do portador de paralisia cerebral: atitudes de professores do ensino fundamental. Revista Brasileira de Educação Especial. v.12, n.1, p.85-100, 2006.

MANZINI, E. J. Considerações sobre a elaboração de roteiro para entrevista semiestruturada. In: MARQUEZINE, M. C.; ALMEIDA, M. A.; OMOTE, S. (Org.) Colóquios sobre pesquisa em Educação Especial. Londrina: Eduel, p. 11-25, 2003.

MILIAN, Q. G.; ALVEZ, R. J. R.; WECHSLER, S. M. et al. Deficiência Intelectual: doze anos de publicações na base Scielo. Revista Psicopedagogia, v.30, n.90, p.64-73, 2013.

PATO, T. R.; SOUZA, D. R.; LEITE, H. P. Epidemiologia da paralisia cerebral. Acta Fisiátrica, v.9, n. 2, p. 71-76, 2002.

TAILÂNDIA. Declaração de Jomtien, de 05 de Março de 1990.

VELDEN, H. F. V. Formação de profissionais em psicologia para atenção às pessoas com deficiência: análise de ementários dos cursos públicos de graduação no país. 146 f. Dissertação (mestrado), Departamento de Psicologia, Universidade Estadual Paulista/SP, 2012. 


\section{Como referenciar este artigo}

LOUZADA, Juliana Cavalcante de Andrade.; MARTINS, Sandra Eli Sartoreto de Oliveira. Educação inclusiva: o olhar do professor sobre a prática pedagógica para o aluno com deficiência no ensino fundamental II. Revista Ibero-Americana de Estudos em Educação, v. 11, n. esp. 2, p.986-999, 2016. Disponível em: <https://dx.doi.org/10.21723/riaee.v11.esp2.p986-999>. E-ISSN: 1982-5587.

\section{Sobre os autores}

${ }^{i}$ Mestranda em Educação Especial. UNESP - Universidade Estadual Paulista. Faculdade de Filosofia e Ciências - Pós-graduação em Educação Especial. Marília - SP - Brasil. 17515-000 julouzada@hotmail.com

ii UNESP - Universidade Estadual Paulista. Faculdade de Filosofia e Ciências - Pós-graduação em Educação Especial. Marília - SP - Brasil. 17515-000 - sandraeli@ marilia.unesp.br 